\section{Suchttherapietage 1999}

\section{Michael Krausz}

The fourth congress on addiction therapies, 'Suchttherapietage', was held in Hamburg on May 25-28, 1999. Eight hundred participants from seven countries reflect the high level of acceptance of this seminar congress. The concept of the congress with lectures on special topics and innovations in addiction therapy and with a great number of symposia, workshops, exercises etc. (more than 130 different events this year) offers a forum for specific information on new developments, for exchange of experiences and for specific further education. This concept was very well received by the participants. This acceptance is confirmed by the annual increase of $10-15 \%$ of the number of participants, by the re-registrations and by the press reports.

This year's special topic was the comorbidity of addictive patients and the resulting need to develop special help offers that take notice of the high coincidence of further mental and physical illnesses of addictive patients. The exchange of experience and the discussions between experts from very different fields of the help system, the psychiatric care system, drug centres, inpatient and outpatient services were extremely fertile, interesting and helpful.

The importance of special offers and the adjustment of general psychiatric care to addictive patients with comorbidity has now been realised in the German-speaking countries. An adequate help system needs an optimal cooperation between general and basic care and special institutions by networks and a sensible division of labour. Many efforts are needed in order to improve treatment philosophies, intervention emphases and the continuity of the therapeutic offer. The specialised medical practices for HIV and hepatitis patients and the care of psychotic patients with an addiction in special departments and complementary services are good examples for adequate care. However, such standards are rather an exception and do not reflect a satisfactory situation in the treatment of multimorbid patients.

Many participants were particularly interested in the development of maintenance treatment and other areas of psychopharmacotherapy in addiction treatment, a subject to which various events were dedicated. Thus, the lectures on buprenorphine or the discussion on the pilot project on heroin prescription were greatly welcomed by the various professional groups. Taking up this interest, the special topic of next year's congress will be 'Psychopharmacotherapy and Addiction'.

The 'Suchttherapietage' are used by many professional groups and persons as as possibility for specific further education, as shown by the mixture of participants consisting of $25 \%$ physicians, $25 \%$ psychologists, $25 \%$ social scientists and social workers and $25 \%$ nursing staff and other professional groups.

The foundation of a German Association for Addiction Medicine during the 'Suchttherapietage' takes up the aspect of further education, since the implementation of basic qualifications in addiction medicine is of major importance to improve our understanding of the role played by medicine in addiction therapy.

In order to ensure a good preparation and high quality of the congress with many innovative offers, the organisors invite you to present now your proposals for seminars and workshops or other events for the 'Suchttherapietage 2000'.

Suchttherapietage 2000, Congress Secretariat

Astrid Kühne/Birgit Hansen

Universitäts-Krankenhaus Eppendorf

Klinik für Psychiatrie und Psychotherapie, Martinistrasse 52

D-20246 Hamburg (Germany)

Tel./Fax +49 40428035121

E-mail: Kuehne@uke.uni-hamburg.de

\begin{tabular}{ll}
\hline KARGER & ( ) 1999 S. Karger AG, Basel \\
Fax +4161306 1234 & \\
$\begin{array}{l}\text { E-Mail karger@karger.ch } \\
\text { www.karger.com }\end{array}$ & $\begin{array}{l}\text { Accessible online at: } \\
\text { www.karger.com/journals/ear }\end{array}$
\end{tabular}

